satisfied, sated, C $m \varepsilon t-i y \varepsilon r, \mathrm{H} i t-\hat{\imath} \varepsilon r, \mathrm{R} l i k i-y \varepsilon r$ see, C mwaisa'n, H kîlay, R ma'sani

sick, C sôv-mware, $\mathrm{H}, \mathrm{R}$ hitmu'n

sigh in one's sleep, C, H lipánapay, R rerr in mwâlu

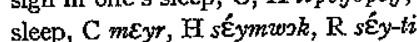

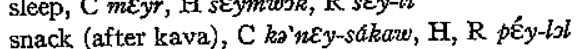

snack (after kava), C $k a^{\prime} n \varepsilon y-s a ́$ a
speak, C lokaya, H, R ma'sani

spouse, C powt $\sim$ prwt, H wa'rak, R likant

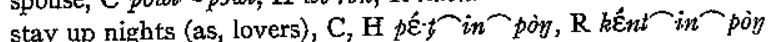

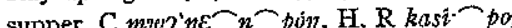

task, see commission

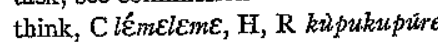

thought, C lamelam, H, R kîpur

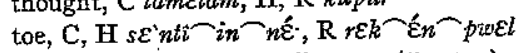

tongue, $\mathrm{C} l 0^{*}\left(l 0^{*} w-\right), \mathrm{H} ; \mathrm{R}$ tinap (timapre-)

tooth, $\mathrm{C} \eta \dot{i}, \mathrm{H}$ inat, $\mathrm{R}$ assay

urinate, C pipi $\cdot s, \mathrm{H}, \mathrm{R}$ kamworsut

vagina, C $p \hat{i} \cdot p i(p \hat{i}-p i y-\}, \mathrm{H}$ unknown, $\mathrm{R}, \hat{\varepsilon} \cdot p a n$

vomit, $\mathrm{C}$ nmmus, $\mathrm{H}, \mathrm{R}$ kàliyáli

wake up (intr.), $\mathrm{C}$ píri-ta, $\mathrm{H}, \mathrm{R} \dot{\sigma} \cdot p$-ala wása

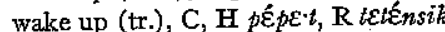

walk, see posture, walk

warm oneself, C, H rếyirray, R kèrakarr ámwaw

wash, $\mathrm{C}, \mathrm{H}$ wîte, $\mathrm{R}$ nil láy-ela

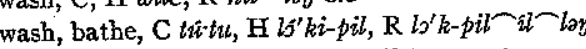

wash hands, C, H o'mwiygm, R sikamewar-ata

wash face, C, H Épreinak, R mà.layi-ta

wash mouth, C mitkumuk, H, R tâzo-to

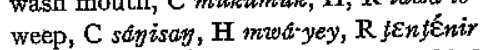

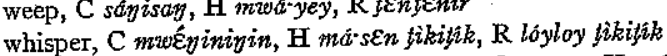

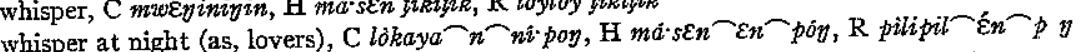

wish, feeling like, C insén, $\mathrm{H}, \mathrm{R}$ küpur

wris

BIBLIOGRAPHY*

Bascom Worat 1946, Ponape: A Pacific Economy in Transition, U. S. Commercial Company

pany, Econor

Garvin, Padr L., 1951a, A Linguistic Report on Ponape: 1. Outhine Ponapean Grammar.

Ponapean Conversational Texts. Unpublished ms. on deposit with Pacific Science Board. , 1951b, Structure and Variation in Language and Culture. In Pres

XXIXth International Congress of Americanists, New Sïssee-Expedition 1908-1910, II

Hambruch, Paut, 1932-1936, Ponape, In: Ergels

Ethnographie: 8 .

* We here quote only publications used for reference in this study. For a critical survey of previous accounts of Ponapean grammar, some of which include references to honorific speech, see Garvin, 1951a, appendix to section I.

\section{Some Head-Hunting Tradttions of Southern New Guinea}

$B y$ JUSTUS M. VAN DER KROEF

TEAD-HUNTING and the complex system of ritual, religion and myth associated with it has at one time or another existed among most of the peoples of Melanesia. Traces of it can be found in numerous legends of the area. The practice has continued to persist, particularly in New Guinea, although both the Dutch and Australian governments have undertaken strong measures to stamp out the custom. Little is actually known of the New Guinea types of head-hunting, beyond that which was studied-or in many instances merely inferred-by Kruyt, Vertenten and Nollen. ${ }^{2}$ Many students, notably Kruyt, did not always allow for the individual differences in headhunting techniques and rituals that exist among the peoples of New Guinea. Thus, though some communities on the Upper Fly River practiced cannibalism in conjunction with head-hunting, this was generally not the case with the hunters along the Southern coast. In the interior communities hunt each other without discrimination; in the South and East custom prohibits the hunting of friendly neighbors. Some groups sanction their head-hunting practices by religious beliefs, while others-particularly the Obadu in the East--do not. The present study is primarily concerned with some practices at one time prevalent among southern communities, notably the Marindese and Boetinese, among whom head-hunting follows a clear pattern of social motivation and moral-religious necessity.

The Marindese (or Marind-anem) ${ }^{3}$ and Boetinese live scattered in some seventy-odd villages near or on the Southern coast, roughly between Okaba and Merauke. Their economy is of a mixed character. Cultivation of sago and coconut, in carefully tended communal garden plots, alternates with occasional hunting of sahan (a species of small kangeroo) and basik (wild boar, akin to the Javanese babi roosah). Until very recently the sexes lived apart, adult males in three or four men's houses of a character identical with similar institutions elsewhere in the Malay Archipelago, houses which are closely related to the drama and the dance of the community. The women and small children live in the low, rambling women's quarters. Government of the communities is in the hands of the men's councils, which have representatives of each men's house; the council acts as a judiciary body and metes out punishment to offenders of custom. Before the active emergence

I Vor der Hake, 1934, pp. 19, 37, 78-84. Legends of cannibalism are probably even older.

2 Kruyt, 1906; Vertenten, 1923, pp. 45-73; Nollen, 1924, pp. 3-19.

${ }^{3}$ Vertenten, p. 46.

4 The influence of the Javanese men's house on the technique of the theater, for example, bas been indicated by Rassers, 1931, p. 431 
of Dutch administrative influence in the area, the villagers lived in virtual isolation, notwithstanding their proximity to the coast. In very recent times, some members of the coastal communities have migrated to the north where the larger administrative centers are located, and upon their return have begun to modernize their communities. But this process has barely begun, and the greater part of the Marindese today adhere essentially to the same old pattern of existence.

\section{TI}

The basic cause of head-hunting is the need for names in a community, The the uniformly for many of the New Guinea tribes that engage in it. Head-hunting has therefore little to do with the desire to increase engage in it. Head-hunting has thexefore litte to do with the desire to increase one's strength by slaying an enemy and keeping his most valuable member the head, in one's possession; nor is the hunt primarily a sort of initiation the head, in one's possession; nor is the hunt primarily a sort of initiation ceremony in which the younger men are expected to show their bravery. The supposition that the head-hunter seeks to acquire the "soul substance" of his vim in order to prolong his own life should be accepted with caution since it is by no means the all-important factor in the hunt.

Most inhabitants of Southern New Guinea, except those few who have become completely westernized and abandoned their traditions, possess more than one name. Some of these are nick-names, derived from a personal amulet, then's house, or an emblem; others are curses or exclamations of joy, said to ave been uttered during feasts or dances, or by the individual's father during copulation following the feasts. Other names may have been acquired during the head-hunt itself, at the time a victim is caught (havek-rik igis), ${ }^{5}$ or when his scalp is being removed (kahasib-rik igis)
triumphantly carried to the men's house (erev-rik igis).

triumphantly carried to the men's house (erev-rik igis). '

A man's real name, however, prized beyond all others, is the head-name (koei-igis) the name of the victim whose head has been acquired. The headname is a badge of honor, with whom the bearer is completely identified. To exchange one's head-name with a friend is therefore the highest honor which one can bestow. For every head-name given to a child means that its father, uncle or other immediate relative has travelled into the interior, and has undergone the dangers that accompany slaying the victim whose head-name on the child. The social pressure behind the of such a name is so great that a child is derided and, indeed, feels inferior unless he possesses his own head-name. Among the Boetinese the child will frequently carry the lower jaw or chin of the victim whose head-name he bears sewed

5 In the Marindese dialect, vowels are long, particularly the $a(a), e(e), o(o), i$ (i) and $u(v)$ "In the Marindese dialect, vow is ar. Consonants are generally short, $\mathbf{j}\left(\mathrm{d}_{3}\right), \mathrm{k}(\mathrm{k}), \mathrm{b}(\mathrm{b}), \mathbf{v}(\mathrm{v})$ The $(\mathrm{p}) \mathrm{h}$ ( $\mathrm{s}$. The $\mathrm{g}$ is sharp (g), ee or a lengthens the vowel. The $\mathrm{h}$ after a vowel is $\mathrm{p}(\mathrm{p}), \mathrm{h}(\mathrm{h}), \mathrm{n}(\mathrm{n}), \mathrm{s}(\mathrm{s})$. The $\mathrm{g}$ is sharp (g), very soft, almost silent. The native wo
dialect, with phonetic values as above. in a little cotton bag around his neck, and mothers keep their children under control by threatening to take this prized possession away from them unless they behave.

Theoretically, no child may be born into the community unless there is a head-name ready for him, and despite the relative absence of any organized family life a father has a moral responsibility to have a head-name in readiness if he is presented with a child. If there is a shortage of head-names, two children, provided they have the same father, may be given one name, though this custom, referred to as zadik-parik, is rare and only occurs when circumstances-such as recent Dutch administrative supervision-make it impossible to go on a head-hunt. As a result, head-names in very recent times have become hereditary, and have taken on the character of western family names. But under normal conditions, and especially if a community is warlike, it frequently occurs that there are head-names to spare, and some children may be given more than one. No Marindese enjoys as much social prestige as the hunter who graciously bestows extra head-names on those children whose own fathers have no names left for them, and many legends deal primarily with those heroes who, in addition to bringing bountiful delicacies to the community, also provided all children with extra head-names. Since no distinction is made between men's or women's names, a ready reservoir of names is one of the chief treasures of any village.

The origin of the desire to acquire a name may perhaps derive from the social prestige accorded a man for individual bravery. The head obtained during a particularly arduous hunt is a permanent symbol of courage. Perhaps a geographic factor may have played a role, since the names of neighboring friendly peoples and of specific locations are still given to dogs and pigs, supposedly in order that they may be remembered better. In some instances, as, for example, among tribes north of the Digoel River, names of woods, creeks, marshes are added to the head-name of the child, to indicate where the victim was caught. It is important that these names be kept fixed in the memory of the people, for every head-hunting village has a definite area in which it may operate. To go beyond the limits and hunt a friendly community is doer, a moral wrong for which the community as a whole must frequently atone.

The Marindese and Boetinese therefore divide mankind into three, or sometimes four categories: the anim- $h a$, i.e., the "real humans"' themselves; the ikom, other inhabitants of New Guinea, their enemies; the poe-ikom, neighboring friendly communities; and, where there has been contact, the poe-anim, or "foreigners," those of non-indigenous origin, such as Europeans and Chinese. The ikom are regarded as inferior in every respect, and exist only as objects of the head-hunt (anim-bake). In the course of time the number of communities classified as ikom grew steadily as the head-hunting village 
increased in numbers and became more daring. With one's immediate neighbors one prefers to be poe-ikom, friendly. This not only insures greater safety, but also has an economic value. Thus the immediate neighbors of the Boetinese but also has and of parts make boats and drums; while in other parts of the forest birds of paradise and cassowaries are plentiful. These commodities are frequently brought to the coast for trading purposes.

Changes in friendship between groups which occur from time to time cause considerable confusion, especially among the older members of the community. In fact, next to the head-hunt itself, the Boetinese regard nothing so dangerous as an attempt to conclude peace with a tribe that was previously ikom. There are no mediators or interpreters involved in the process. Those wish to conclude a treaty secretly approach the enemy and leave near their village a bundle of presents, usually some chalk and betel-nut, ingredients which are largely in demand for chewing among most inhabitants of Southern New Guinea. If the ikom is receptive to this gesture, its members will deposit an equal amount of chalk and betel next to the gift. However, only too frequently the $i k o m$ practices the old ruse of going through the motions of friendship, while members of the $i k a m$ community ready themselves for combat and ambush the emissaries when they return to see how their gift has been received.

The traditional areas where the Marindese and Boetinese hunted heads were the forest regions on either bank of the Digoel River, and the area between the border line of Northern New Guinea and the Fly River. The boundary the border line of Northern New Guinea and the Fith the extreme eastern line separating East and West New Guinea coincides with the extreme eastern boundary of head-hunting territory. Hundreds, if not thousands have been the victims of head-hunting in these regions. When about the turn of the century the Government of the Netherlands established immediate control over some fo approximately of this area, the total number of Marindese a This figure closely coincided with the number of victims whose heads passed into the possession of villages of head hunters; that is, for the benefit of one generation of Marindese, some 15;000 persons in the interior were illed. In the years between 1910 and 1912 some one hundred heads were

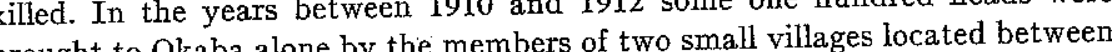
(his inordinately large numthe Bian River and Wambi. One explanation for this ber, quite in excess of those required to name the children, is a general desire for revenge, johan heis ipe. Those head-hunters who were themselves victims during a raiding party demand vengeance, and this fact becomes an added incentive to go into the koei-mirav, or hunting area. Unsuspecting friendly villagers frequently fall victim to the pressure in a community for more head-names, and younger men, anxious to acquire a position of prestige, may attack members of a poe-ikom. It should be emphasized, however, that head-hunting, at least among the majority of inhabitants of New Guinea, is not practiced for purposes of revenge alone, nor is it necessarily an aftermath of combat in connection with some traditional feud, nor yet primarily "an integral part of the maturation process (in the cultural sense) symbolizing the achievement of adult status in society," as one student has suggested. ${ }^{6}$ These other factors may or may not enter into it, but they are not fundamental to the quest for names, which is the primary purpose.

The question arises as to how a hunter comes to know the name of his victim. In cases of individual hunting, as when for example one villager decides to take the head of an individual or group of individuals casually met on the beach, near the village or in the forest, this involves a deliberate ruse and an element of surprise. The hunter will induce his victim to eat with him, or chew some betel with him or give him other evidences of friendship. In the ensuing conversation, names and places of origin are usually mentioned. The hunter will then suddenly attack his victim, and take his head. On occasion an entire village will practice such ruses upon unsuspecting passersby. Vertenten ${ }^{7}$ mentions the village of Nowari, southeast of Merauke, where travellers were invited to stay over for a while and frequently remained permanently. To alleviate suspicion the hunters of Nowari permitted many travellers to pass unmolested, so that the element of surprise could be retained, whenever they did attack.

When an expedition goes into the interior to hunt heads, spies are usually sent in advance. These bide themselves in the bush close to the village to observe its life, and also to learn the names which the villagers call each other. Elaborate preparations are made, sometimes weeks in advance. On occasion, when it has not been possible to learn the names of the victims, survivors of the village, especially young children, are forced to tell the names of those who have fallen. Some villages near the Upper Digoel River have even been known to "baptize" the heads of those victims whose names were unknown during the feast held immediately after the return of a successful expedition. However, names of these newly "baptized" heads have less prestige than a true head-name, having what might be called an emergency status.

Contrary to many assertions, both men and women in Southern New Guinea participate in head-hunting, and it is very likely that this is also the case elsewhere on the island. Women do not ordinarily witness the actual beheading, but their presence is required to care for the small children of the village which has been the object of the hunt, since generally only infants of the village escape with their lives. Since the journey to the hunting territory is frequently long and difficult, only young men and women of reputed stamina are permitted to participate in it, though sometimes they are accompanied by a few elders who act as guides or advisers. The iwag (young women)

${ }^{5}$ Reed, 1943, p. 54, describing the Sepik (Kaguia) River natives.

${ }^{7}$ Vertenten, p. 49. 
the afternoon following the snake rites. If the destination of the group is directly in the interior the Digoel River would usually be followed. The long boats leave one after the other, each containing its complement of hunters, boats leave one after the other, each containing its compleme in the bow. The and carrying quantities of carefully protected sago and rice in the bow. The entire village usually accompanies the hunters part of the way, afterwards to return and string the lahuv, a long ceremonial cord, in which an indefinite number of knots have been tied, across two trees. Each day an elder unties one knot, so that the community may know how much time has passed since the hunters departed.

Meanwhile the hunters, directed by the elders, approach their destination. On either side of the river nature betrays the presence of humans, and the hunters are quick to detect these signs. The javoen kai, or small footpath through the bush leading away from the river, an abandoned fish-net or boat, through the bush leading away from the river, an abandoned fish-net or boat, a sago vat or deserted garden are all witnesses to human existence. Camp is generally made only at prearranged localities. Sometimes a scout may meet the main party to indicate the way, or to tell which village is to be attacked. When the hunters approach their prey they take the utmost care not to betray themselves. One of the elders softly proclaims the gamo over the group, a magic formula said to make one invisible. Chalk, grass, clay and feathers are smeared or fastened to the head and upper part of the body as a kind of camouflage. Then, during the night the hunters approach as close to the village as flage. Then, during the night the hunters approach as close to the village as possible, place themselves in ambush and obtain last minute directions from the scouts. The elders now whisper magic formulas over the village that are said to cause deep sleep, so that its inhabitants will not suspect their impending said to cause deemen, except a few irrepressible ones, withdraw some distance away from the village.

Finally, with the first sign of the new day, the attack is launched with a battle cry, usually given by the person who first conceived of the venture. The cries are very much alike: johan koei ma man eher zib, "I have come to take your heads." Others join in. When the hunters are inside the village compound, each repeats the common call to action: "Let us fight!" During the struggle these cries are sounded over and over, as loudly as possible, in order to induce fear, which, with the element of surprise, determines the success of the attack. The villagers are usually too sleepy or confused to offer much resistance. A few may seek refuge in the jungle; others may make a show of fighting, and these are later honored by the hunters in the subsequent head feast as "the brave." Frequently the hunters will shoot flaming arrows into the huts, forcing all inhabitants to run out into the open, where they are mas sacred.

Wounded or not, the victims are first of all, in so far as is possible, secured and placed in a group, in order to determine their names, the scouts assisting in this procedure. Then the slaughter begins. Every captured member of the village over about twelve years of age has his head cut off. Younger children, who are old enough to walk, are "adopted" by the hunters, being taken in charge by the women. Male and female victims are all killed, babes in arms are left next to the beheaded bodies of their mothers; these are the "insignificant ones" left to grow up if they can, and multiply in order to provide future victims. Women and children are generally not present at the beheading for this is men's work. Some bloodthirsty young women, whose daring and cruelty have earned them a name are, however, sometimes permitted to participate. The bamboo knife alone is used for beheading. One cuts deep into the neck of the victim until the spinal cord is reached. Then custom prescribes that the hunter seize his victim by the hair, and using his knife now as a sort of axe, attempt to sever the spinal cord. This may be quite difficult, and the head is ultimately severed only by much wrenching and twisting. Among the Boetinese it is a mark of distinction and of strength to be able to sever the head with at the most two twists, one to the left (imo) and one backwards and up (goedimo). The corpse, drenched in blood, is contemptuously cast aside. The bodies are not generally buried, but left in the compound, where the wild life of the forest soon disposes of them.

Beheading requires considerable practice, and the elders instruct the novices in this. Frequently an attempt leads to bungling and butchery. However, the victim has one last right. If he so desires, he may be beheaded standing up, which poses considerable difficulty for the hunter, particularly if he is shorter. By standing erect, the victim also has a chance to seize the knife, or some other weapon; and can perhaps dispose of one or two of the hunters before he himself falls. He who captured the victim has the right to the latter's name and head, but at least among the Marindese he is not obliged personally to cut off the head.

Cannibalism, contrary to many assertions, is or was the exception rather than the rule among the peoples of New Guinea. Many groups, and certainly the Marindese and Boetinese even regard it as morally wrong. Stirling's assertion, for example, that among the Bamu and Goaribari of the Fly River district "unrestricted cannibalism is the rule" "should be regarded with considerable reservation. In the first place, only on occasion does necessity drive a head-hunting party to eat human flesh, and this is regarded as exceptional. Secondly, few if any tribes permit women to commit cannibalism. Finally, among many tribes, only elders, and where they exist, medicine men are allowed to eat human flesh. In the instances where a tribe is known to practice cannibalism, it is usually due to the occasional excesses in which the young hunters indulge immediately after a village has been decimated. In the region about Okaba, certain hunting communities preserve human fat, which in

S Stirling, 1943, p. 20. 
cases of severe illness among the members is fried with the sago and eaten. Some Marindese may occasionally preserve part of the upper arm or thigh of a victim, not to be eaten, but to be used during the head-feast. Customarily, the victim, not to bead are some vertebrae, only parts of the body that are taken along with the head are some vertebrae, particularly of the neck, which are used in the head-feast, where they fulfil an indispensable function. But an indiscriminate consumption of human flesh, or of any particular part of the human body, is generally rare. Nor has the present writer found evidence among the Southern New Guinea head hunters that genital organs of either. sex are preserved because of magical properties. The supposed connection that may exist between the phallocrypt and certain concepts and rituals of fertility or the life cycle, which Reed has suggested, ${ }^{10}$ requires documentation. Certainly no connection of this kind exists among the Marindese or Boetinese.

The ways in which heads are prepared varies considerably among the communities of the South. The Koalese of the Upper Digoel River take only the scalp and parts of the lower jaw, so that the form of the face is lost. The the form of the face is lost. The inside of the head is filled with clay and grass, and the outside pressed into kangeroo skin and then dried, the eye sockets then being filled with shells or beads. The Marindese are perhaps more thorough. An incision is made in the sin at the back of the neck and extended to the crown of the head. The skin is then separated from the head on either side, and the scalp is removed and placed over a coconut to dry. Then the skull is cleaned, all flesh is cut off the eyes are removed and the brain cavities are emptied. In order to do this as quickly as possible, a hole is frequently made at the base of the skull to facilitate the draining of blood and brains. A small.flexible strip of bamboo is placed over the nose and fastened to the lower forehead after which the cavities of the cheek bones are eyes are filled with clay or coconut marrow and given as lifelike an appearance as possible. The skulls are now hung to dry near the fire; this completes the first stage.

Custom prescribes that this must be done immediately after the head is Cined and in any event before the hunters return home. It requires much obtained, and in hunters may take all the time they desire to ornament and otherwise finish the heads. This consists of tying small strips of bamboo across the forehead and the placing the scalp over it, fitting the latter as snugly as possible. Each skull is next provided with a hair braid, several feet long and covered with glittering or beads and sometimes with small pebbles, brightly polished and painted a dark red. Finally a thin strip of bamboo is placed through the nose; the head ${ }^{10}$ Reed, p. 40.

II Marindese children will try to capture birds, cut off their heads and practice the incisions on them. Vertenten, p. 73. is then ready to hang in the men's house or the women's quarters.

During the return journey, it is customary that boar or cassowaries are hunted, since their meat is needed for the feast.. On occasion the group may decide to pillage in the neighborhood of the depopulated village. Generally however, not more than one village is attacked at a time, since the hunters are anxious to return home. Now there is singing in the boats usually simple melodies expressing the wish to return and see the doev or coast. Doev ah oh "Jong live the beach" is an exclamation frequently heard during the return journey. And at the first signs of home, those who only a few hours before had beheaded almost an entire village now weep at the sight of the familiar huts and gardens; for weeping is regarded as normal, and seems almost conditioned when a party returns home.

As soon as the boats are beached, a celebration begins. The young hunters, in high spirits, throw their bamboo vessels containing chalk against the stems of the palm trees, enveloping the village in white dust and causing intermittent explosions; if frecrackers are to be had from Chinese peddlers, these are fired. Women and elders stand in two rows, holding bananas, coconut and sago candy for the warriors. Meanwhile all the heads are brought to one of the men's houses and hung up together on the center cross beam, there to remain until the head-feast. The house is declared out of bounds for all but a few elders, and the villagers stand at a distance and peer into the dark interior. Curiosity and excitement mounts, especially when members of neighboring Marindese or Boetinese villages come for a visit, having been told of the hunters' return. The standard praise of the guests is the formula: teepo ti ikom isak ah oh, "you have all been very brave." Each hunter narrates his deeds during the raid, nor does he stint his imagination; the compound seems to be overrun with people, divided into small clusters around the hunters. Occasionally one hears laughter, or the prolonged as oh, denoting sympathetic attention or approval. A good talker will hold his audience for the greater part of the day, and-as elsewhere-will himself ultimately come to believe in what he is saying.

\section{IV}

Traditionally the hunt culminates in an elaborate feast, celebrating the capture of the heads, which among the majority of the head hunting communities of Southern New Guinea is also a focal point of religious observance and mythological commemoration. It is during this feast that rituals and traditions acquire meaning, and the social motives underlying the head-hunt are fitted into an over-all pattern of approved behavior. Preparations for the feast are elaborate, and may sometimes take as much as a year. Generally it is held immediately after the next harvest, when the community possesses an abundance of sago, coconut meat, rice and other foods. The period of prepara- 
tion is divided into several stages, each taking its name from the goods or activities associated with it.

The first stage is the soeba "bamboo." Bamboo is taken from the surrounding forest to make a fence around the feasting area, a rectangle of about 300 by 150 feet, containing the men's house where the heads hang. This fence may by 150 feet, containing the with long strands of coconut fibre and dried sago leaves. During the second stage, called essara, "seats" or "couches," sleeping couches and benches with a shelter over them are constructed around the edge fhe seating or sleeping capacity of these is about 1,500 During takav, "kindling wood," or "logs," the third stage, wood is piled fairly close to the center of the feasting area, to provide fuel for baking the large heavy sago pastry, which is sometimes as large as three feet in diameter. The fourth period is called sakai, literally "nest of termites," when termite nests built in heavy rocks, and valued for their thickness, are cleaned out and used in which the pastry is baked. During the sakai in the building of stall ovens in which the pastry is baked. During the sakat there is $d a$ hore, or beating of sago, huge quantities of this being stored in the feasting area; at the same time the dirari or bamboo vats are likewise placed in readiness.

Next comes the period of beisam, "beautiful hair," during which the men prepare their coiffures for the feast, arranging their hair in long braids, covered with beads or pearls, feathers of the bird of paradise and long strips of clay molded like a snake, placed in circular fashion on top of the head. The women's molded is also adorned, but this requires less time, since among the Boetinese women simply add a strand of coconut fibre to each braid so as to give a veiled like appearance. The sixth stage, termed ahat bes, finds the villagers making whe bamboo fence surrounding the feasting area on which food and private possessions are hung during the feast, since experience has taught that during the feast whatever gets in the way of the dancers will be destroyed underfoot. They also procure heavy wooden sticks with which to chase away pigs and dogs. Next comes the kav manop meb, "potato harvest." Potatoes are gathered from the garden and are hung in bunches around the feasting area. A few high bamboo trees are also ornamented, so that from afar peo that the village is celebrating. During this period a sturdy young bamboo is erected at the center of the feasting area so that the heads young bamboo is erected at the see.

The eighth and final stage is koem boe, during which the villagers gather fresh coconut meat. This is a sure sign that the festivities are about to begin, fresh coconut meat. This is a sure sign that the fill not keep for any length of time. In a dition, supplementary quantities of pork or kangeroo meat are obtained in addition, supplementares period of preparation the women are kept busy preparing vast quantities of food, while the elders are engaged in supervising the ornamentation of the feasting area, the construction of various symbols to be used during the head dance, arranging hospitality for important guests and the like.

The feast begins as suddenly as the head-hunters' attack. The signal is given by one of the elders, and at his bidding the heavy drums are heard. The hunters form a single file at the feasting area and, slowly walking around, begin to chant the ajasee song. Before he enters the compound, every hunter obtains those heads to which he is entitled from the men's his left hand, while in the right he holds his knife. The procession goes around and around until suddenly the monotonous ajasee is broken by the introduction of a new melody, a high pitched staccato song, called wasipee, begun by those persons who first conceived of the hunt. The wasipee, in its later stages, assumes a narrative character and tells of the arduous hunt itself, the bravery of the hunters and of the singer in particular, of the joy that the new heads will bring to the unborn children who can now safely appear without having to be ashamed because no head-name is ready for them, and the pleasures of copulation which customarily follow the feast. This song lasts for hours; when one singer stops, another takes over. Meanwhile the women have entered the compound with their children and seat themselves on the benches. When at last the sun rises, the singers finally become silent and, exhausted, sleep during the greater part of the day.

The next night there is a new procession and a new dance. This is marked by the singing of the $s a m b z i$, a combination of a religious chant, war song and summary of communal symbols and heroism. Like the ajasee it is a monotonous melody, sung to the accompaniment of the drums, but unlike the ajasee the guests of the village join in singing it, for the neighboring communities regard it as an invitation. to visit the celebration. Long files of nearby villagers, each person carrying a large torch, half dance, half walk to the feasting area; they sing their own $s a m b z i$. The song is climaxed when the bunter who originally proposed the hunt ascends the small rostrum in the center of the feasting area, here he stands swaying to the rhythm of the drums, his long plumes waving, his left arm carrying the heads stretched high above.his head, until the samb zi generally dies amidst a hush of awe.

The final stage of the ceremony, like the feast or the head hunt itself, begins very suddenly. This final stage is concerned with mimicry and simple pantomime. Elders, dressed in richly colored costumes, begin to portray legendary heroes of the village, and go through mock combat while they chant long narratives of individual courage. They again cover themselves with leaves and green cloth, and while one of them carries a crudely constructed snake's head made of bamboo, cloth and sago leaves before him, the others follow him in a single file, weaving as a group around and around the feasting area. Now the true symbolism of the feast comes to light. Each hunter takes his heads and, chanting, joins the file, rhythmically performing the dance-steps as the pro- 
cession circles the compound. By this act of joining the serpent, in a manner similar to that before the hunt began, he merges his courage and invincibility into that of the group as a whole. Suddenly another group of elders sweeps down upon the "serpent," attempting to divide it by breaking the file. But as the Marindese say: "The snake cannot die," and the elders who attempt to destroy it are themselves absorbed as they join the others.

This final rite thus portrays the Marindese participation in the life-cycle, The coming of a new generation -is absorbed by the symbol of group invincibility and immortality. At the same time this act raises the head-hunt above the level of mere wanton cruelty. For this small group of people of New Guinea, the hunt has a religious meaning as well; it is a necessary part that the individual plays in the never-ending a being born reaching maturity, and dying. The hunter may die, but pre he nomes of the dead will be borne by the heads he has captured ensure that the nom immortality is attained. Their those who come after them and so an element of imor will live on.

memory will not end with their death, since their names will live on.

The dancing continues, but one by one the men leave the compound to have sexual relations with the women, for a child conceived during the feast is said to be exceptionally strong and wise. Furthermore; copulation at this the sexual an extension of the rite of the serpent since as the life cycle

act at this time acquires a symbolic religious meaning.
After the feast the fence is torn down and the heads are hung in the respective men's houses, to be further adorned. Notwithstanding all the eflort expended on them, however, the climate and the numerous ants soon take their toll. The scalp becomes rough and disintegrates, and the skull itself shrinks. Customarily a number of heads are hung in a bunch inside the house, but in the case of old and dilapidated skulls they are unceremoniously strung together and rigged near the men's house emblem, where any unknowing of coconut. If a skull is so far gone that it can no longer be preserved, the hunter will first carefully salvage the chin or lower jaw and place these in a special bag, the rest being thrown away. The bag is hung over the hunter's sleeping couch, or else hung in the dhe vertebrae of the neck are never thrown doorway of the men's house. The vertebrae of the neck are never thrown away, but are either worn, or used to ornament the inside of the hoution they are said to be so imbued with supernatural powers of protectic it is maintained, no village with sufficient kutaio (vertebrae) has ever been successfully attacked by other hunters. As the weeks pass, the memory of the lives on in the numerous tales recounted about the fires in the evening, and with this memory the desire to go once more and hear the familiar cry of the hunt becomes stronger. For though the frequency of the hunt has steadily hunt becomes stronger. For though the frequency of the hunt decreased over the past decades, most traditional head hunting villages, particularly those in the interior near the Upper Fly River in Papua, seek to go at least once a year.

\section{Michigan State College}

East Lansing, Michigan

\section{BIPETOGRAPHY}

BaAL, J. vaN, 1947, Over Wegen en Drijfveren der Religie.

HAKE, G. F. VOR DER, 1934. Ziekte, Dood en Ritueel in den Maleisehen Archipel.

HET, G. J., 1948. Slangenfiguren in het initiatie ritueel van de Geelvink Baai. Pp. 231-234 in H. Hoogenberk, ed. Cultureel Indï, Bloemlezing uit de eerste zes jaren, 1939-1945.

KRUYT, A. C., 1906. Gesin en Gewelschapsleven bij de volken van Nederlandsch-Indië.

Nollex, J. J., 1924. De Roomsch-Katholieke Missie en hare verhouding tot de zeden der Inlandsche Bevolking van Nederlandsch-Indië.

RÁSSERS, W. H., 1931. Over de Oorsprong van het Javaansche Toneel. Bijdragen tot de TaalLand-en Volkenkunde van Nederlandsch-Indië, vol. 88, pp. 424-465.

REED, STEPHEN W., 1943. The Making of Modern New Guinea.

StrRLInc, W. W., 1943. The Native Peoples of New Grinea.

VERTENTEN, P., 1923. Het Koppensnellen in Zuid Nieuw Guinea. Bijdragen tot de Taal-Land-en Volkenkunde van Nederlandsch-Indï̈, vol. 79, pp. 45-73.

WIRz, P., 1922, Die Marind-Anim von Höllandisch-Sud-New-Guinea. 